Article

\title{
Beyond Calendars and Maps: Rethinking Time and Space for Effective Knowledge Governance in Protected Areas
}

\author{
Claudia Múnera-Roldán ${ }^{1, *(1)}$, Dirk J. Roux ${ }^{2,3}$, Matthew J. Colloff ${ }^{1}$ and Lorrae van Kerkhoff ${ }^{1}$ (i) \\ 1 Fenner School of Environment and Society, The Australian National University, Canberra, ACT 2601, \\ Australia; matthew.colloff@anu.edu.au (M.J.C.); lorrae.vankerkhoff@anu.edu.au (L.v.K.) \\ 2 Scientific Services, South African National Parks, George 6530, South Africa; dirk.roux@sanparks.org \\ 3 Sustainability Research Unit, Nelson Mandela University, George 6530, South Africa \\ * Correspondence: claudia.munera@anu.edu.au; Tel.: +61-261-251-865
}

Received: 10 July 2020; Accepted: 22 August 2020; Published: 25 August 2020

\begin{abstract}
Protected area managers rely on relevant, credible, and legitimate knowledge. However, an increase in the rate, extent, severity, and magnitude of the impacts of drivers of change (e.g., climate change, altered land use, and demand for natural resources) is affecting the response capacity of managers and their agencies. We address temporal aspects of knowledge governance by exploring time-related characteristics of information and decision-making processes in protected areas. These areas represent artefacts where the past (e.g., geological periods and evolutionary processes), the present (e.g., biodiversity richness), and the future (e.g., protection of ecosystem services for future generations) are intimately connected and integrated. However, temporal horizons linked with spatial scales are often neglected or misinterpreted in environmental management plans and monitoring programs. In this paper, we present a framework to address multi-dimensional understandings of knowledge-based processes for managing protected areas to guide researchers, managers, and practitioners to consider temporal horizons, spatial scales, different knowledge systems, and future decisions. We propose that dealing with uncertain futures starts with understanding the knowledge governance context that shapes decision-making processes, explicitly embracing temporal dimensions of information in decision-making at different scales. We present examples from South Africa and Colombia to illustrate the concepts. This framework can help to enable a reflexive practice, identify pathways or transitions to enable actions and connect knowledge for effective conservation of protected areas.
\end{abstract}

Keywords: protected areas; knowledge governance; cross-scale management; knowledge systems; temporal dimensions; time

\section{Introduction}

Protected areas are artefacts where the past, present, and future are connected and integrated. As public assets, these designated conservation areas are boundary objects-spaces where multiple actors share information and interact [1], connecting diverse social-ecological elements, each with specific temporalities. Elements from the past are represented by landscapes, geological and ecological processes, refuges as sites and symbols of Pleistocene extinctions and historical climates [2], or the deep time evidence of the unfolding relationships between people and nature. Through time, human societies have evolved narratives that reflect different ways of conceptualizing, interpreting, and interacting with nature, justifying what is considered important or of value (including tangible and intangible values) and how to manage nature. In this context, protected areas represent the stage on which particular 
societal interpretations of nature are played out [3]. Human agency is expressed in conceiving and deciding what, why, and how nature in these protected areas needs to be conserved.

As complex social-ecological systems, protected areas comprise multiple temporal and spatial scales where human and non-human actors connect [4], although not necessarily at the same pace. Time-related characteristics in ecological systems include ecological and evolutionary processes including variables such as seasonality, frequency, and duration of interacting biotic and abiotic processes that are organized hierarchically $[5,6]$. For human societies, time provides the cues for specific practices, for instance, traditional local and Aboriginal communities organize their activities according to natural, seasonal tempos (i.e., harvesting, ceremonies, fishing), using customary and experiential knowledge that comes from memories and stories transmitted from one generation to the next. In this perspective, knowledge is active, rather than static and processed [7]; memories represent information from the environment that has been filtered and interpreted by human agents [8]. For modern human societies, time is entrained to deal with administrative issues, the creation of daily routines embedded in time-related metaphors like calendars, clocks, diaries, and time zones. In the case of protected areas, time is related with management and operational plans to meet conservation goals, with specific timeframes for implementation measured in months or years.

Managing and planning biodiversity conservation is complex, with inherent uncertainties and contested interests affecting decision-making [9]. In managing for environmental sustainability—including protected areas-practitioners rely on relevant, credible, and legitimate information for their decision-making processes [10]. Although advances have been made to better integrate information for managing natural resources, two issues are still evident: the constant call for better, more effective science indicates a persistent frustration and perceived lag between science and action [11], and there remain many cultural and institutional barriers to effectively use scientific information [12,13].

Unpredictable change is inherent to managing protected areas as complex systems and managers often are prepared to deal with it [14]. However, the increase in frequency and severity of impacts of drivers of change [15] affects institutional and individual capacity to respond to such events and use information for decision-making; in part, because of the inherent tensions managers face in reconciling management timescales and ecological timescales. For example, the speed and rate of extreme climate events and their impacts can extend beyond both the timeframe of a management plan and boundaries of a protected area or a country; its effects overlapping different temporal and spatial scales and cascading across biophysical systems [16]. Such events limit the ability of managers to identify and use climate information for decision-making processes [17,18], design monitoring systems, and comprehend ecological transformations and how people and nature respond to climate change $[19,20]$. In short, the additional complexity of climate variability limits the capacity of managers to design conservation strategies that effectively address adaptation to climate change.

What does time mean for managing protected areas under uncertain changing conditions, and how can people plan for, and select the best information to deal with unexpected changes? To help answer these questions, we propose that careful consideration of temporal and spatial aspects could provide benefits for knowledge creation and its application for managing natural resources in times of high uncertainty and rapid change. We argue that the linear conceptualization of temporal dimensions, implemented and reinforced through the use of modern calendars and clocks (as well as timetables, diaries and agendas), might be constraining our capacity to understand complex interactions in social-ecological systems at multiple spatial and temporal scales. Land managers operate in at least two spatio-temporal scales: the here and now and day-to-day of their responsibilities, as well as the scale at which social-ecological processes play out in the longer term at a landscape or regional scale [21,22]. However, managers are often constrained by the need to respond to specific timeframes mandated by the tools for management or urgent responses to meet administrative or political objectives, rather than operating at more extensive spatio-temporal scales beyond administrative constraints and maps [23].

To facilitate a multi-dimensional understanding of knowledge-based processes, we propose that dealing with uncertain futures starts with a better understanding of the knowledge governance context 
and decision-making processes involved in adapting protected areas management to climate change. Drawing primarily from civic epistemologies studies [24], the manuscript is divided in four sections. In the first section we present concepts related to time, presenting the idea of the "eternally unfolding present" $[25,26]$ to enable actionable knowledge and practice under uncertain futures. The second section focuses on knowledge governance, and the implications for decision-making in the context of protected areas management. In the third section we propose a framework that can help understand time-related issues in relation to identifying, accessing, and using knowledge in ways that reflect the multi-dimensional scales within which protected areas operate. In the fourth section we illustrate our concepts with practical examples from the South African National Parks (SANParks) experience with Strategic Adaptive Management, and interviews performed during a study of knowledge governance under climate change in Colombia [18]. In the concluding section, we highlight the importance of understanding time related processes in planning and practice, to facilitate addressing multidimensional processes where protected areas managers operate.

\section{Timescapes and Time Perspective}

\subsection{Understanding Time: Connecting Past, Present, and Future}

Time helps human societies, individuals, and institutions to plan and organize activities, connect with specific moments in history, and, in separating the past from the future, it facilitates the making of prospective decisions $[27,28]$. In every society, different conceptions and perceptions of time coexist. A key assumption in planning for the future is that time is "continuous, linear, unidirectional and irreversible" [28] (p. 140); time is continuous in that it keeps moving on and does not comprise discrete units, unidirectional in that one event follows the other, even if repeated in cycles, and irreversible in that it cannot go backwards. The perception of time as linear or circular is not only a subjective construction but also a cultural one [28].

In modern industrial societies, and the management of natural resources, time is the " ... disciplining coordination metrics of modern clocks and calendar $\ldots$ by which modern society measures and responds to change and categorically distinguishes the 'past' from the 'future'" [27] (p. 3). Ecological processes and ecological responses to external variables (including human disturbances) operate in longer spatial and temporal scales. This inherent mismatch between human planning and the rhythms of nature constrains the capacity to recognize, access, and use alternative tempos from Indigenous and Local Knowledge (ILK); such knowledge comprises individual and collective memories, their relation to and interpretation of territory, and environmental change [29].

From a temporal perspective, the duality of nature and society that is inherent in natural resource management does not exist in Indigenous societies [27,30]. For example, a landscape represents both abstract and physical aspects, where time and space are intrinsically related and evident (i.e., in geological eras, evolutionary processes, and human habitation). A landscape is created in the eyes and mind of the observer, so its boundaries depend, in part, on the observer's capability for interpretation and imagination [30] and represent both tangible and intangible elements of cultural relationships between people and nature. From landscapes, we can move to the idea of timescapes as described by Adam [30], to acknowledge complex environmental phenomena and inherent temporalities relevant to social-ecological systems. Timescapes encompass time-related characteristics (seasons, rhythms, pace, cycles, environmental change, memories) linked to the natural environment. The concept acknowledges change and how past events and memories influence the present while offering options for the future: "A timescape perspective enables us to integrate scientific and everyday knowledge and the constitutive cultural Self with the workings of nature" [30] (p. 55).

In protected areas and in the context of climate change, timescapes can help integrate diverse forms of knowledge to understand how climate change-related impacts cascade across scales [16] and levels of governance, including different temporal and spatial scales that go beyond the boundaries of protected areas. A timescape includes the complex responses to changes in social-ecological systems, 
the different interpretations of risk, and the urgency to act. It implies active learning from past events and diverse actors, crafting new knowledge in the present, and envisioning future scenarios under climate change.

\subsection{Temporal Dynamics and Conservation Goals}

This interaction of different timelines (past, present, future) is common in biodiversity conservation and climate adaptation studies. However, sometimes knowledge-related work does not explicitly consider temporalities. Knowledge baselines for managing protected areas are often based on species inventories, which are limited to a specific location and time. Long-term monitoring can address temporal coverage from single inventories [31]. Defining indicators of the conservation goals, alongside Thresholds of Potential Concern (TPC) can help managers and scientists to identify levels of unacceptable change in the system under management [32,33]. Ecological responses have specific temporal hierarchies, representing long-term system variability [6]. Understanding the differences between individual ecological responses (events) and processes can facilitate the identification of information needs and the design of monitoring systems. Monitoring ecological processes and responses-not just particular biotic groups-can provide a better understanding of the complex, non-linear processes of ecological responses through time, and help to understand patterns and trajectories across scales (see e.g., [5] for a watershed case covering multiple protected areas, and [34] for long term elephant and fire savannah management in Kruger National Park).

As drivers of change and their impacts operate at multiple scales, monitoring systems might consider units beyond the protected area boundaries to facilitate an understanding of the complex dynamics of social-ecological systems. Tools for forecasting and prediction can help to visualize scenarios for the future and identify information needs for conservation goals [35,36]. These prediction tools have an important temporal basis enabling time perspective: being aware of how events follow each other over time, and the role of past events in shaping the choices made today for the future [37]. It emphasizes the role of everyday practice, experience and learning, placing an actor (individuals and institutions) in an "eternally unfolding present" [25,26].

Memory is an important element of time-related perspectives. In "The importance of a certain slowness", Cilliers [8] describes the relevance of knowledge and memory, and its role to help anticipation of what is to come as complex systems unfold over time. He points out that memory is the "persistence of certain states of the system, of carrying something from the past over into the future". This does not mean to glorify the past, but allowing past events to linger in the present is how we can process information, interpret new events to help inform anticipation of the future, and counter the illusion that "if we live quickly and efficiently in the present we are somehow closer to reality" [8] (p. 108). Knowledge creation is a social process that requires learning, reflection, and dialogue, all of which take time. Integrating diverse forms of knowledge and memories provide a means to interpret the changes and evaluate the rhythm, impacts, and extent of drivers of change.

As different stakeholders in protected areas usually hold a diversity of beliefs, values, and knowledge, and different interpretations of time and change, exploring knowledge governance arrangements can help to identify potential political, cultural or customary tensions when selecting and applying knowledge for planning [38]. In the next section, we discuss how these temporal dimensions connect with knowledge-based processes.

\section{Knowledge Governance: Accessing, Using, and Sharing Information}

\subsection{Creating Meaning, Crafting Knowledge}

Words and stories shared by a group shape its identity and create meaning for mutual ideas and concepts. Meaning is produced through interactions with the world and reinforced by the selected choice of words, language, and metaphors used in everyday interactions [39]. This collective creation of meaning is closely connected with knowledge creation. Knowledge-based processes are 
context-dependent: institutions, rules, geographies, as well as individual and collective preferences, shape how knowledge is created, shared, and applied. A variety of cultural and political settings frame how people perceive, understand, and respond to natural phenomena and processes, including the 'how', 'what', and 'whose' of knowledge and its use [40].

Acknowledging the complexity and varied forms of knowledge, in this paper we consider two domains: scientific knowledge, and ILK [41]; ILK evokes the strong, long-standing linkages of Indigenous people, but also of more 'recent' communities (e.g., pastoralists or farmers) to their natural environments, and their specific interpretations of environmental change. Protected areas provide a good example of the interplay (or lack thereof) between knowledge and action produced by different actors operating at different spatial and temporal scales. As a 'community of practice' [39], protected area managers reinforce meaning through maps, regulations, and management plans, the implementation of which is measured in calendar time. In contrast, Indigenous communities create meaning and make sense of their world through dreams, stories, ceremonies, and traditional practices, where calendars and clocks are less relevant [42]. As explained by Cuvi [43] (p. 81), ILK ${ }^{1}$ is created through practice, learning, and openness to experiment. These individual and collective interpretations of the world, with different understandings of risk and future climates, can lead to different environmental rules and standards, which can then enable or constrain adaptation options [29]. In managing complex social-ecological systems, it is important to acknowledge the plurality of visions and human dimensions shaping science-policy relationships [44].

In doing their work, protected area managers are expected to find, produce, and use information to connect management objectives with specific time horizons for their implementation, monitoring and evaluation [45]. In deciding what knowledge to use for planning and making decisions to deal with changing environments, protected area managers are conditioned by their decision contexts. Gorddard et al. [46] explain the decision-context as a societal construction whereby held human values (such as the motivation to conserve nature), societal and institutional rules (formal and informal actions, norms and practices for managing and planning), and knowledge (the diverse ways used by people to make sense and understand the world) influence how people make decisions. When certain values or rules predominate it affects how certain forms of knowledge are included or excluded, depending on what values, rules and knowledge the decision makers consider credible, legitimate and important (see examples of values, rules, and knowledge interactions from Australia in [46,47]; for Colombian examples, see [48]). In the next section, we provide details of this knowledge-practice interaction.

\subsection{Producing, Co-producing and Governing Knowledge}

In linking science with management decisions, there is a trend to move from the knowledge deficit model [11] to co-production as a way to promote actionable science while considering the complexity of challenges in managing natural resources under climate change [49]. Although co-production has different definitions, we follow Wyborn et al. [50] (p, 3.2): "processes that iteratively unite ways of knowing and acting -including ideas, norms, practices, and discourses leading to mutual reinforcement and reciprocal transformation of societal outcomes". This definition addresses context-related aspects of producing and applying knowledge and the governance of knowledge-based processes in situations where there are different interpretations and ways of creating meaning in the setting of goals, as is the case for protected areas.

Knowledge exchange, understood as processes of creating, sharing, interpreting, accessing and using knowledge, is one way of understanding the interplay that is required for co-production, and is not straightforward [13]. Understanding contexts and barriers can facilitate the identification of options to enable knowledge exchange for more efficient decision-making and management. Such an approach requires an understanding of the governance of knowledge: the overarching rules of how

1 Here ILK is inferred by the authors; in Cuvi (2019) Indigenous knowledge is mentioned, but does not refer explicitly to ILK. 
societies engage in knowledge creation (including the preferred types of knowledge for making decisions) and how to share, protect, use, or access that knowledge [38]. Knowledge governance "can help to understand the role of knowledge and learning in the governance of complex societal issues" [51], including knowledge-based arrangements (formal and informal rules) for decision making, and facilitate more effective interactions between knowledge and practice. Knowledge governance is often confused with knowledge management, however the latter involves the day-to-day practice of organization along with accessing and using information and is not considered here.

Understanding knowledge governance can help to address temporal mismatches when deciding how to address conflicts of interests, identify ways to move beyond traditional practices and embrace innovative options for managing natural resources. A first step is to identify existing knowledge governance systems, for example the so-called 'loading dock' model [50,52], as well as institutional arrangements in use, for example boundary organizations, knowledge exchange, and embedded researchers [13,53]. These models are often framed by high-level processes and complex arrangements that shape the way society governs knowledge-based processes (known as civic epistemology), which therefore influence knowledge systems (such as institutional arrangements for science-policy interaction), as well as interventions and knowledge management responses for the application and translation of knowledge into action [38].

Knowledge-based processes (including co-production) might benefit from explicitly embracing different temporal dimensions. In collaborative interdisciplinary research, different perceptions of the urgency to solve problems, and the different paces to create knowledge by different disciplines and communities of practice, influence how we define timeframes for action [54]. In the next section, we present alternatives to explicitly explore the diverse conceptions of time, how it is conveyed in knowledge-based processes, to open opportunities for productive collaboration and dialogue with multiple stakeholders in and around the protected area, rather than mismatched understandings based on preconceptions or assumptions of time.

\title{
4. Framework for Multidimensional Knowledge-based Processes
}

\begin{abstract}
"Some years ago, we started reflecting on fragile ecosystems and climate change, and we realized, what are we going to do with the glaciers? Who is working on that? What management actions are needed?"
\end{abstract}

Manager, Colombian National Parks, 2016

In its conception and implementation, management of natural assets often neglects or misinterprets temporal horizons when designing environmental monitoring programs and decision-making processes. To facilitate an understanding of time in relation to knowledge processes and decision making, we propose a framework to evaluate current knowledge-based processes in protected areas management and planning, as a guide to understanding the timescapes in which managers operate. Acknowledging that management of conservation goals operates within spatial and temporal limits, the framework is a guide to addressing the complex interactions of multidimensional management in a practical way while identifying options to move beyond constrained and utilitarian concepts of time (such as calendars) in relation to knowledge selection, usage, and the implementation of policies. Each protected area context is different, and it is likely that some managers are already applying some of these ideas. The framework aims to enable managers to navigate options for integrating practice (e.g., management effectiveness), applying science and technical knowledge (e.g., monitoring systems), and connecting diverse knowledge systems and memories to understand social-ecological processes and responses to drivers of change. For example, ILK can provide a richer vision of social-ecological processes, based on multigenerational observations and practice [55].

The framework is based on the idea of ecological reflexivity [56], involving recognition (monitoring impacts and system changes while anticipating future conditions), reflection (learning from past events, rethinking values and practices and envisioning), and response (reviewing objectives and 
values and reconfiguration of processes and practices). We integrate these elements into a simplified version of protected areas decision making (Figure 1). The framework includes the idea of the here-and-now that protected area managers face every day in their jobs. The present represents the living memory (including previous learning) gained by practice, anticipation of what is going to happen, and careful observation of the outcomes. We present some guidance questions (Figure 2 and Appendix A) intended to facilitate the reflexive process, guide discussions, and help managers exploring multidimensional knowledge-based processes in their current practice. These questions can happen as part of a deliberative process to update management plans or monitoring systems and can guide managers navigate and understand how current knowledge systems address time across scales. The framework and suggested options are not prescriptive, but aim to guide the discussion to identify what information is useful, whose knowledge is relevant, and elements to consider in designing monitoring systems that allow managers to capture systems dynamics in space and time.

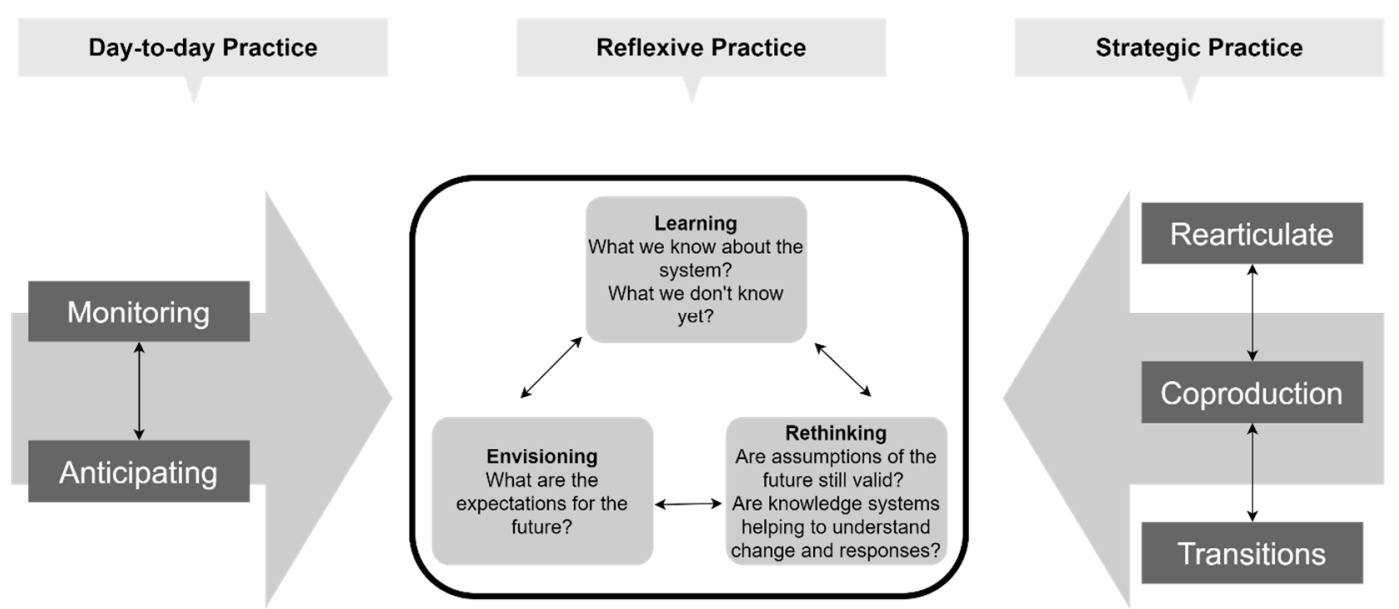

Figure 1. A framework to address multi-dimensional knowledge-based processes for management of protected areas. The day-to-day practice on the left focuses on monitoring social-ecological processes and anticipating or thinking about future conditions of the system. The reflexive practice (center) emphasizes learning from previous knowledge-based processes, rethinking assumptions and knowledge systems, and envisioning expectations. To the right, the strategic practice level focuses on how to rearticulate or transition to alternative forms of knowledge and management. Modified from Dryzek and Pickering [56].

The first category is the day-to-day practice, or operational level, which represents the activities to meet the strategic objectives, including anticipating changes and monitoring current conditions. This level is critical to provide feedback to strategic decisions and update planning. Then, an intermediate level of reflexive practice, to allow learning about past projects, planning and activities, rethinking the effectiveness of knowledge systems used to understand change, and envisioning expectations for the future. Finally, the strategic level corresponds with decisions related to broad, overarching, long-term goals that span geographical and temporal scales. These can include setting collective visions for a protected area and surrounding landscapes, align management plans with Indigenous Plans of Life (a participatory planning instrument to reimagine Indigenous futures), developing and managing a network of protected areas, or complying with international conventions. 


\begin{tabular}{lll}
\hline - What is the knowledge exchange model \\
in use?
\end{tabular}

Figure 2. Illustrative example of the guiding questions and options for managers, to guide the discussion about multidimensional knowledge-based processes. Tables A1-A3 expand the questions at each level.

The information required to understand changes in ecological functions and the cascade effects of disturbances across scales require more than data collected over narrow temporal and spatial scales [57]. The relationship between information needs and decision-making timeframes might have different interpretations in management and planning [18] (p. 45), affecting how information is produced, selected, and used. Moreover, our lack of clear knowledge about the type, speed, and extent of ecosystem transformation as consequence of climate change challenges how we make decisions, our interpretation of time, affecting knowledge-based processes for managing protected areas. For example, when designing monitoring systems, scientists and managers often omit the response timeframes of ecological processes, or use incomplete datasets that do not reflect the interconnectedness of ecosystem processes at different spatial and temporal scales [5] or the underlying complexity of ecosystem services and the processes that provide them. In this sense, we understand ecosystem services as biophysically and socially co-created; their use and interpretation evolve over time according to societal preferences [58]. As ecosystems, biodiversity and social processes are structured hierarchically across temporal and spatial scales, protected area managers can benefit from explicitly addressing temporal scales, territorial dynamics and ecological processes when using knowledge and information.

Careful linking of management effectiveness times, with long-term monitoring results can help visualize changes and responses while allowing learning, testing of management options, the effectiveness of information collected and evaluation of thresholds of change. At the strategic level, the rethinking of information and knowledge needs involves a process of collective reflexivity on how to adjust knowledge systems for managing change and understanding that management of future ecological transformation requires dynamic management, learning and eventually rethinking and changing practices, structures and conservation approaches consistent with what has been learnt and observed. Although this re-articulation is not straightforward, it can occur as small transitions in 
current approaches that facilitate reframing knowledge governance processes and incorporating other forms of knowledge (e.g., see four conceptual transitions to enable future adaptation in [48]).

The example illustrated in Figure 3 shows how ecological processes and information needs on conservation goals distribute across spatio-temporal scales to support predictions of ecological responses and change over the longer term. Anticipatory processes can benefit in setting TPCs, and reflecting on the observed responses of biota to climate and other drivers of change, managers and researchers will be able to better understand the mechanisms of climate impacts, the sensitivity of natural systems and implications for transformation in the protected area. Human needs and their dependence on ecosystem services play an important role in defining conservation goals, but also as underlying drivers of environmental change. Social TPCs can complement ecological ones to allow an integral understanding of processes and responses of the social-ecological system [59].

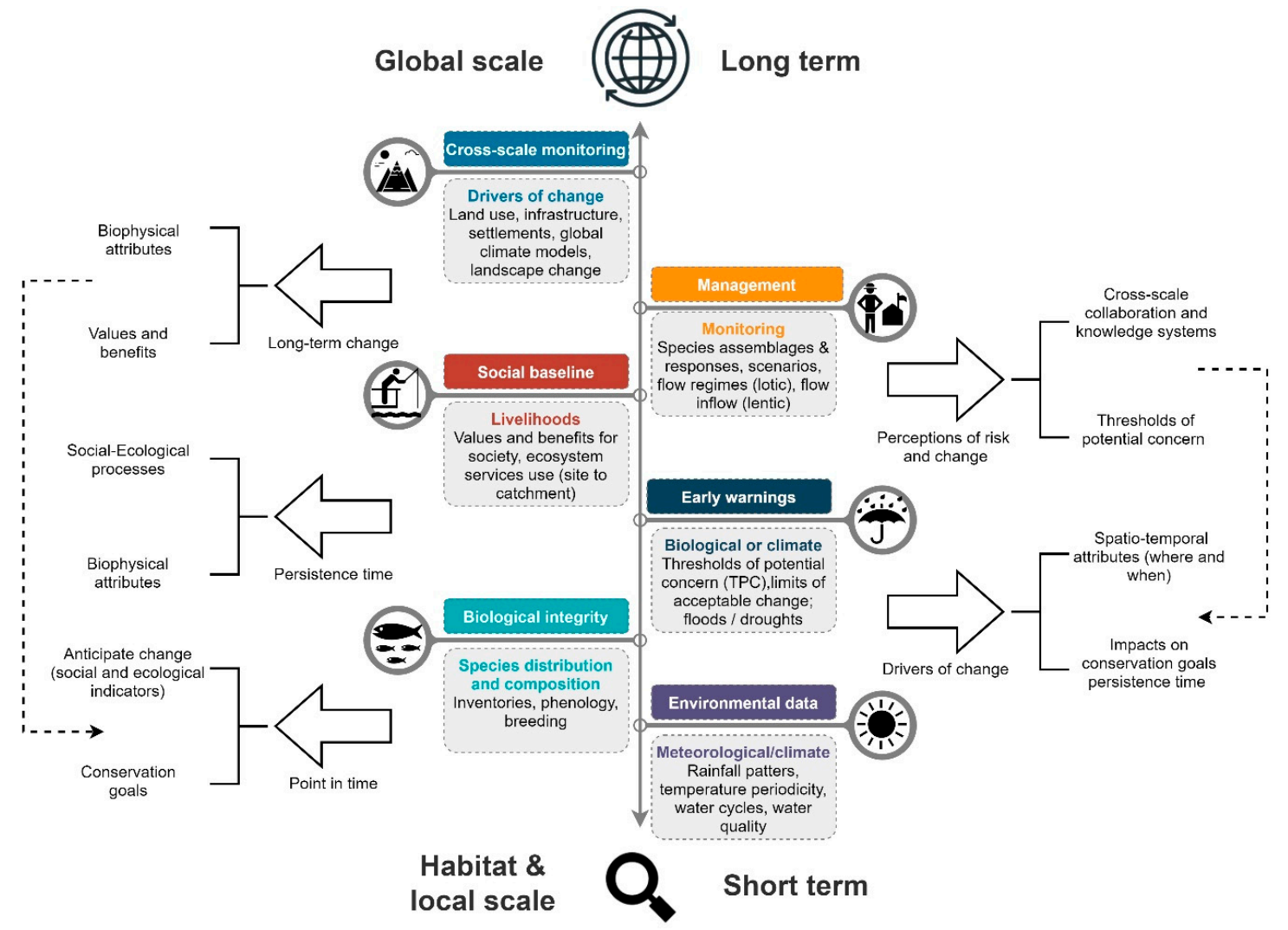

Figure 3. Overview of social-ecological processes and information needs on conservation goals for managing protected areas across spatio-temporal scales, from the short-term and local scale (bottom) to the long-term, large scale (top). Information from local level can help to understand conservation goals and social-ecological responses across scales, and the overall performance of ecological processes and functions. Data collected at the local scale (e.g., inventories) are limited to a moment in time and space; long-term monitoring can address temporal coverage from single inventories. Identifying early warnings like Thresholds of Potential Concern (TPC) facilitates an understanding of systems responses to drivers of change. Drivers of change can be events at local level/small temporal scales, or located at larger spatiotemporal scales, even outside the protected area, their impacts cascading across biophysical systems.

Human responses to environmental change play an important role in the dynamic nature of knowledge production. These responses can include changes in agricultural practices, reforestation and restoration efforts, human migrations or shifts in use of natural resources [20]. Observing and recognizing these responses within and outside the protected area can facilitate learning and experiential 
management, which is essential to enabling adaptive practices, while adjusting information needs, timeframes, and planning, which is essential for moving into the strategic practice level.

Finally, it is important to recognize the knowledge governance and decision-making context in the protected area. Each case is different and human perceptions and interpretations of the conservation values influence the creation of knowledge for managing these areas. An open dialogue with relevant stakeholders might allow agreement about objectives and desired future goals as well as identify the most relevant socio-ecological processes that require monitoring and management, while defining the thresholds of potential concern and limits of acceptable change $[9,59]$. In understanding the type of information available, including the timeframes for which climate information exists, managers can reflect on current practices and management questions, update planning tools, and improve decision making processes.

\section{Reconciling Calendar Time with Reflexive Practice}

So far, we have considered a framework for multidimensional knowledge-based processes for protected areas management. We emphasize that recognizing temporal dynamics related to production of knowledge is essential to support decision making and planning of social-ecological systems. It can help in understanding complex temporal patterns, the interaction at different geographical scales, and biotic responses to different drivers of change [6]. However, some questions remain outstanding. Environmental managers in the Anthropocene need to be more aware of driver-response dynamics through time and rethink temporal horizons and spatial scales, given the complex context under which multiple actors interact and make decisions [4]. We suggest this framework can help reconcile the different motivations for protecting natural assets when defining and implementing management and adaptation options under uncertain and changing conditions.

Calendar timeframes are useful when dealing with administrative issues, assessing changes in the conditions and guiding future management [60]. Independent on the knowledge model in use, applying a reflexivity process for the management of protected areas can facilitate a time perspective approach and identify relevant information from past events, while observing, documenting, and learning from previous practices, and investing that knowledge in new meaning in the present and into the future. This approach includes thinking about what information is available now or what information might be relevant to understand socio-ecological processes and responses in relation to the conservation goals, while reflecting on the biophysical characteristics that span through space and time and can support an understanding of ecological responses to climate change. In this context, the time perspective can help design monitoring systems with a more systemic vision and facilitate adaptation to a changing climate.

We present examples from South Africa and Colombia to illustrate how calendar times can be reconciled with reflexive practice. An ongoing collaboration between the authors helped to infer how this is happening in each country. The different governance models and knowledge systems of these countries allowed the authors to explore-through an inductive process-the assumptions for the framework. The example from South Africa comes from SANParks extensive experience with adaptive management; for Colombia, we used data collected through a co-production and knowledge governance study [18].

\subsection{South African Approach: Strategic Adaptive Management and Reflexivity}

How different is the framework presented here (Figure 1) from adaptive management? Adaptive management has become a foundation of effective environmental management in contexts characterized by high levels of ecological uncertainty [61]. It stems from acknowledging that ecological (and social-ecological) systems are complex, that understanding of such systems is imperfect and partial, and that the responsible way to proceed with management in these contexts is to learn by doing, and to adapt actions as new understanding emerges. It achieves this by integrating research, planning, management, and monitoring in repeated cycles of learning [62]. Adaptive management 
is a systematic approach to improving the management process by purposefully learning from the outcomes of management actions.

Strategic Adaptive Management (SAM) is a version of adaptive management that has been iteratively developed and implemented by SANParks for more than 20 years [9,63]. SAM has been applied to a variety of social-ecological challenges, from relatively narrow (e.g., management of elephant populations [64]) to extremely broad (e.g., management of a national park; for more information, see Roux et al. in review) application contexts. Regardless of the context, SAM consists of four interlinked and dynamic sub-processes [65]: adaptive governance (co-producing the 'rules of the game' at a range of levels, from national legislation to park policy to local rules shaped by stakeholder norms and values); adaptive planning (co-creating a vision and management objectives for addressing a specific social-ecological challenge); adaptive implementation (designing and implementing management measures, research experiments and monitoring programs to action the above objectives and enable learning from their outcomes); and adaptive evaluation (assessing and reflecting on the outcomes of implementation against the vision and objectives, to inform ongoing learning and adaptation).

During adaptive planning, diverse stakeholders participate in face-to-face dialogues during which they deliberate the social values, changing contexts (social, technological, economic, environmental, and political) and vital attributes (special or unique features) of the social-ecological system of concern that should guide future decision making. These dialogues provide the basis for jointly articulating a vision and setting management objectives. The tacit knowledge of participants, which reflects past experiences, converges into an explicit vision statement and objectives for directing management in the future.

During adaptive implementation, ongoing engagement between agency scientists, park management, and stakeholder groups enables the consideration of multiple knowledge sources, including experiential and tacit understanding as well as science-based information, to inform decision options. Selected management actions are implemented in conjunction with complementary research projects and monitoring programs, to enable purposeful learning by doing. Monitoring of key indicators, and setting TPCs for these indicators, serve as forms of feedback to stimulate reflection, especially when thresholds are being approached or exceeded.

Adaptive evaluation refers to formal and informal assessment of and reflection on progress towards achieving the vision and set objectives, in line with the reflexive level. Lessons learned through these processes provide forms of feedback to, at least in theory, update or adapt the rules of the game (adaptive governance), the vision and objectives (adaptive planning) and management actions, research agendas, and monitoring programs (adaptive implementation). The SAM process incorporates memories and prior knowledge of stakeholders to anticipate and articulate a desired future state, which in turn guides sense-making in the present through combined actions, monitoring, learning, and research.

The SAM approach aligns to some degree with the framework. However, even SAM, with its strong emphasis on getting "consensus on a desired future state across a range of value systems" [62], has shortcomings. Park management plans are embedded in national legislation, which render their planning, implementation, and evaluation processes less flexible, responsive, and adaptive to natural social-ecological cycles than ideal [62] (e.g., policy determines when a plan gets revised, and not necessarily readiness of the social-ecological system; compliance culture stifles experimentation; and resource constraints limits dialogue with stakeholders). However, there are opportunities to rearticulate the rules. For example, where management plans include a program on climate change, ongoing learning about, and improved understanding of, climate as a driver of social and ecological change will help to update the normative rules of the game, to better understand information needs for climate adaptation, update monitoring systems, facilitate envisioning options, and rethinking assumptions. 


\subsection{Colombian Protected Areas: Linking Knowledge and Management Beyond the Calendar}

The Colombian protected areas national agency has been actively working to understand the hazards and impacts related to climate change and their implications for managing protected areas. The Future-proofing Conservation project worked with protected area managers to rethink management options in the context of climate change and uncertainty about future socio-ecological transformation [48]. Using semi-structured interviews, the quotes below were documented by C.M. during the project to identify the different forms of knowledge related to climate and ecosystem services that are used for long-term planning and management, and how knowledge governance can be enhanced for strategic thinking and decision making. Full details on the methodological approach and methods are presented in Munera and van Kerkhoff [18]. The quotes in this manuscript have not been published previously.

Knowledge creation is an evolving process of past experiences and everyday interaction with the world, in which reflection is encouraged and learning is incorporated into practice. In Colombia, managers recognize these attributes, and are in the process of implementing reflexive practice: "we have [scientific] information; [now] is a moment to stop, review and analyse what we have, looking at the future, to identify gaps, reflect on other issues we would need to cover and to develop a long-term vision for managing protected areas" (Int. 3). This quote demonstrates the relevance of practices of learning, collaboration, and openness to change. In applying long-term thinking, it is important to consider choices and decisions made today, while being open to accepting and using alternative knowledges to understand territorial processes to support implementation of conservation strategies and connect with different concepts of time and knowledge.

For Colombian protected areas the learning process is allowing reflection on current practices to integrate risk into management and better connect with territory: "we are working on understanding if restoration is an adaptation action or not, what criteria we need to consider and how to apply it in practice to decide if we need to update zoning in the management plan. Managing risk is helping to better understand the territory and identify places where landslides can affect indigenous communities or farmers" (Int. 4). This process is facilitating managers to integrate other forms of knowledge alongside scientific information, enabling the strategic thinking necessary to manage uncertain futures and planning for climate adaptation [18].

Climate change and uncertainty of climate-related information have been reported as a major barrier for making decisions [66], so is the poor understanding of climate change impacts and mechanisms of climate sensitivity for species and ecological processes [17]. These limitations, plus a sense of urgency in trying to avoid ecological change, might prevent managers from fully considering social-ecological dynamics and potential mismatches in the information available to them. Climate change is opening the door to update current practice: "climate change is forcing us to look beyond the boundaries of the protected area and have more integral planning" (Int. 12). Although this openness to incorporating new knowledge was in response to a technical deficit (a lack of instruments for monitoring climate variables), it demonstrates that it is possible to rethink practice [18]. Instead of a reactive use of information, when a climate event triggers a response [66], managers can benefit from careful consideration of how past events have shaped present-day ecosystems, and cross-scale ecological responses of the conservation goals. Such considerations include the identification of conditions that may trigger other responses and can give managers agency to identify the most relevant information to act as the future unfolds.

A diversity of worldviews in a context of managing protected areas and knowledge-based processes can facilitate the reconfiguration and rethinking of managing multidimensional protected areas systems. Indigenous communities have specific timescapes, intrinsically linked with their interpretation of the environment across temporal and spatial scales. In their view, life and nature are not seen as discrete units, but as processes that have specific cycles linked with belief systems and cosmology. For Indigenous groups, decisions on their land requires revisiting their ancestral history [42,55], a view that demonstrates a deep time perspective and connectedness with the territory. Some Colombian 
protected areas that are co-managed by indigenous groups are in the process of adjusting modern administrative timeframes to local tempos, set by nature and people's connection with it $[42,67]$, and, when setting meetings, managers need to consider environmental rhythms (e.g., river flows), customs (e.g., funerals, wakes, and dreams) and their timing with nature. Although these parks are managed under State rules, local practices have been influencing the way the National Protected Areas agency interprets their role and governance in areas inhabited by Indigenous communities [42].

\subsection{Implications for Future Management}

As we started developing the ideas for this manuscript, an unprecedented bushfire season ravaged parts of Australia. Although bushfires are expected every summer, their severity and extent had enormous impacts on National Parks, wildlife, and livelihoods, challenging the response capacity to deal with them and questioning how to integrate Aboriginal customary practices of fire management. Fire regimes in Australia are well documented, especially in relation with the human practices and Aboriginal knowledge [68]. Aboriginal customary practices to manage the land using fire have been proven to reduce the density of shrubby understory plants and fuel loads, thereby reducing the intensity of bushfires $[69,70]$. Incorporating Indigenous fire management into Australian protected areas can be regarded as a direct adaptation measure to manage dynamic ecosystems under a changing climate or as an indirect adaptation measure, which aims to maintain ecosystems in their current configuration, depending on context and perspective [71]. Integrating ILK with modern technology and science can be beneficial, but requires changes in knowledge governance hierarchies, reflection on future expectations of conservation goals, and defining how much change managers and local communities are willing to accept to facilitate system monitoring, management, and action [72].

Understanding and accepting change (ecological change, change in practice, change in knowledge, and change in the territory) is a first step to rethink management of biodiversity under changing environmental conditions and climate. This perspective constitutes a shift in the way we conceptualize nature and management, and therefore the epistemic context and responses. In documenting dynamics of change and adaptation in epistemic communities (specifically practitioners and researchers working in ecological restoration), Hirsch and Long [73] found that when practitioners move their expectations from stable climates and ecological models to recognize the possibility that historic conditions and preconceived assumptions of nature might no longer exist, they were able to reorient practice and goals. This shift in thinking and practice might bring new paradigms, concepts, perspectives, and ideas, enabling the integration of new information and knowledge for strategic adaptive management.

Through a reflexive practice, managers, local communities, and other relevant stakeholders (information providers included) can discuss and identify TPCs and limits of acceptable change and identify management responses in relation to change, while adapting information needs. This shift in the science-practice paradigm is reported in Kruger National Park [9], where SAM was a response from managers who realized that instead of avoiding change, it would be better to understand and anticipate it, while working to identify conservation goals and thresholds of potential concern. This re-framing allows a transition from business-as-usual management to an approach where the complexity of social-ecological dynamics is recognized. Rapid change is embraced to allow room for co-learning, to understand change and the multiple values, knowledge, and interpretations of nature.

The interaction between different epistemic communities can help to update knowledge-based processes, as reported for Colombian protected areas [18]. This interaction demonstrates that biodiversity conservation planning processes can accommodate a range of different outcomes and worldviews, while recognizing how environmental decisions connect or impact other sectors. Anticipating the future is not about speculating, but being able to consider future consequences of decisions made today, having agency and willingness to change and take action, question current alternatives, being able to connect with other forms of knowledge, disciplines, and stakeholders, and being aware of others (nature or society) when making decisions [37]. 


\section{Conclusions}

The framework we present provides some guidance to connect multiple dimensions where knowledge and decision-making interact in the management of protected areas. We consider it is adaptable to specific context and circumstances, considering the knowledge governance model in use, and taking advantage of managers' experience and daily interaction with social-ecological systems to facilitate learning and co-production. Also, the framework incorporates a recognition that social-ecological processes and drivers of change have different time horizons and operate at different spatial scales. Rethinking and changing knowledge systems in use can take advantage of the diverse ways people make sense of the present and envision the future.

The custodianship of the present for future generations is augmented by an appreciation of the past and the acknowledgement of the plurality of knowledge systems. Use of diverse knowledge systems takes advantage of a richer set of memories, facilitating the process of anticipation and adaptation to new conditions, dealing with surprises, and reconciling collective agendas and expectations $[8,74]$. In a context of climate change, governance determines how we respond to new and uncertain climate impacts, and influences whether and how strategies are implemented [75]. Considering the challenges posed by climate change, and other drivers, we need more flexible management of biodiversity and ecosystem services while incorporating multiple visions, temporalities, processes, and interpretations of the world. The concept of timescapes [30], can help managers to understand time related processes in their areas, rethink assumptions, and explicitly consider and integrate multidimensional knowledge-based processes in mental models and practice. For example, because timescapes encompass seasons, natural rhythms and cycles, and memories of natural events, they can be used in TPC thinking and SAM by paying greater attention to changes in the return interval and seasonal shifts in events related to drivers of change, such as bushfires, floods, droughts, and cyclones. The effects of such changes on the integrity of protected areas and surrounding landscapes, and the consequences for achievability of management objectives then form a basis for a more reflexive approach to management.

Reconciling calendar management times with reflexive practice is possible, as we have presented here. South Africa National Parks is working on it, while Colombian protected areas have been accommodating diverse knowledge systems to complement technical knowledge and transitioning to adjust practices and rules. Although we probably will not find an ultimate suitable and cost-effective solution to deal with complex problems in a rapidly changing world, as Fernández [11] (p. 172) points out, we need to remember "new circumstances and context, including past solutions, require ongoing work because we are dealing with co-evolving systems". Accepting this challenge requires for us to stop, contemplate, and understand the moment, as well as to be conscious about how our actions and knowledge are connected and can impact future social, political, and ecological outcomes. Embracing a bit of slowness is important to better identify, evaluate, and deploy the knowledge required to deal with future changes, beyond just responding to "efficient" calendar times. We finish quoting an old Italian proverb: chi va piano, va sano e va lontano (whoever goes slowly, goes safely and goes far).

Author Contributions: Conceptualization, C.M.-R., M.J.C., D.J.R., L.v.K.; investigation C.M.-R., D.J.R., L.v.K.; formal analysis: C.M.-R.; writing, review and editing, C.M.-R., D.J.R, M.J.C, L.v.K. All authors have read and agreed to the published version of the manuscript.

Funding: This research received no external funding.

Acknowledgments: Some of the information presented here was collected during the Future-Proofing Conservation project where C.M. and L.v.K. where involved, funded by Luc Hoffmann Institute and with collaboration from Parques Nacionales Naturales de Colombia-PNN and WWF Colombia. C.M has a scholarship from the Endeavour Leadership Program. We thank Carina Wyborn (Luc Hoffmann Institute) for reviewing the manuscript and her valuable comments.

Conflicts of Interest: The authors declare no conflict of interest. 


\section{Appendix A}

Table A1. Guiding questions for protected area managers to facilitate the reflexivity process in multidimensional knowledge-based processes, and options to consider for the day-to-day practice level. Words highlighted in bold represent some key ideas and issues to consider.

\begin{tabular}{|c|c|c|}
\hline Guiding Questions & Options & References \\
\hline $\begin{array}{l}\text { What is the current model of knowledge } \\
\text { governance in use? }\end{array}$ & $\begin{array}{l}\text { Constant dialogue between managers, practitioners } \\
\text { and scientists to follow up system responses and } \\
\text { 'novelties. Even under a loading dock knowledge } \\
\text { transfer model, managers can have a dialogue with } \\
\text { scientists to refine information needs. } \\
\text { Co-production, interdisciplinarity and socio-cultural } \\
\text { diversity to integrate local knowledge can facilitate } \\
\text { understanding of different needs, expectations, and } \\
\text { social-ecological responses. } \\
\text { Evaluate costs and needs for data collection, } \\
\text { including where to host the data, funding, and } \\
\text { capacity to analyse and interpret it in the long term }\end{array}$ & {$[12,13,50,52,53]$} \\
\hline $\begin{array}{l}\text { What is the main conservation goal (e.g., } \\
\text { biophysical attributes, ecosystems } \\
\text { services, ecological processes) and what } \\
\text { information better capture conservation } \\
\text { goals responses to drivers of change? }\end{array}$ & $\begin{array}{l}\text { Inventories and surveys provide a first glimpse of } \\
\text { conservation goals status but are limited to narrow } \\
\text { spatio-temporal scales. } \\
\text { Evaluate survey characteristics, frequency of data } \\
\text { collected, and applicability of results. Historical data } \\
\text { can be useful to understand the system and anticipate } \\
\text { responses, important to evaluate availability and } \\
\text { quality (e.g., gaps in time or space) of datasets. } \\
\text { Identify indicators that can help understand climate } \\
\text { change as a factor influencing ecological integrity } \\
\text { (e.g., early warnings systems-floods and droughts) }\end{array}$ & {$[5,31,76,77]$} \\
\hline
\end{tabular}

Conservation objectives can have a narrow or broad spatio-temporal scale; drivers of change can be inside, or outside the protected area.

Where are the ecological processes and drivers of change located?

Evaluate which methods for data collection best captures processes and drivers of change at different scales.

Identify the quality and origin of the drivers of change (e.g., endogenous change, exogenous-agriculture, anthropogenic climate change-related)

Information about social-ecological responses at smaller spatial scales (and over short periods) can help, over time, to connect to broader scales (even if this is not the original objective) but requires consistency to avoid information gaps.

What temporal and spatial scales are more relevant to monitor conservation goals and social-ecological processes?
Consider establishing long-term monitoring systems of ecological processes and monitoring impacts of external drivers of change.

Understand persistence time of conservation goals to improve design of monitoring systems and observe responses and trends to anticipate future changes

Define indicators and thresholds of potential concern of these indicators, co-produced with managers, scientists, and communities to track social-ecological responses, define future

How much change are managers and stakeholders willing to accept in relation of social-ecological systems? expectations, limits of acceptable change and decide when to intervene.

Complementary to quantitative tools, qualitative tools can help predict system responses and cascade effects of disturbances 
Table A2. Guiding questions for protected area managers to facilitate the reflexivity process in multidimensional knowledge-based processes at the reflexive practice level. Words highlighted in bold represent some key ideas and issues to consider.

\begin{tabular}{|c|c|c|}
\hline Guiding Questions & Options & References \\
\hline $\begin{array}{l}\text { Are managers and scientists understanding } \\
\text { response times and social-ecological } \\
\text { systems responses? }\end{array}$ & $\begin{array}{l}\text { Evaluate if current information systems and } \\
\text { data quality allow managers and other } \\
\text { relevant stakeholders to understand } \\
\text { ecological processes, functions, and responses } \\
\text { to disturbances. } \\
\text { Conceptual models and mental maps can } \\
\text { help design monitoring, understand system } \\
\text { dynamics, connect knowledge systems, and } \\
\text { identify management options }\end{array}$ & {$[9,31,82-84]$} \\
\hline $\begin{array}{c}\text { What was learnt from the previous practice } \\
\text { and monitoring? }\end{array}$ & $\begin{array}{l}\text { Allow time for co-learning and evaluate } \\
\text { social-ecological responses in deciding if, } \\
\text { and when to intervene, including } \\
\text { understanding and learning from human } \\
\text { responses to ecological transformation } \\
\text { through time }\end{array}$ & {$[48,85]$} \\
\hline $\begin{array}{l}\text { Are current monitoring systems and } \\
\text { management effectiveness processes } \\
\text { adequately capturing responses and } \\
\text { changes of socio-ecological systems across } \\
\text { temporal and spatial scales? }\end{array}$ & $\begin{array}{c}\text { Review and update monitoring systems to } \\
\text { capture knowledge and learning from } \\
\text { different actors and facilitate future decisions. } \\
\text { Evaluate if monitoring system timeframes } \\
\text { are adequate to follow social-ecological } \\
\text { responses, inform decision-making processes, } \\
\text { communicate risks, and facilitate stakeholder } \\
\text { engagement. } \\
\text { Evaluate if management effectiveness results } \\
\text { can help to understand changes in } \\
\text { social-ecological systems }\end{array}$ & {$[78,86]$} \\
\hline $\begin{array}{l}\text { Can observations from stakeholders } \\
\text { outside the protected area and local } \\
\text { knowledge, help to understand human and } \\
\text { nature responses to drivers of change? }\end{array}$ & $\begin{array}{l}\text { Evaluate and update thresholds of potential } \\
\text { concern to ensure monitoring systems are } \\
\text { capturing ecological responses across scales } \\
\text { and enabling action. } \\
\text { Identify potential collaborators for } \\
\text { monitoring ecological processes outside the } \\
\text { protected area }\end{array}$ & {$[18,59]$} \\
\hline $\begin{array}{l}\text { Are future expectations for the conservation } \\
\text { goals in the still valid and relevant? }\end{array}$ & $\begin{array}{l}\text { Under conditions of uncertainty and complex } \\
\text { systems, envisioning and futures thinking } \\
\text { approaches can help visualize future } \\
\text { scenarios and identify actions that can be } \\
\text { done in the present }\end{array}$ & {$[35,36,48]$} \\
\hline
\end{tabular}


Table A3. Guiding questions for protected area managers to facilitate the reflexivity process in multidimensional knowledge-based processes at the strategic planning level. Words highlighted in bold represent some key ideas and issues to consider.

\begin{tabular}{|c|c|c|}
\hline Guiding Questions & Options & References \\
\hline $\begin{array}{l}\text { Under scenarios of ecological } \\
\text { change, is the long-term vision } \\
\text { of the protected area inclusive of } \\
\text { the beliefs, livelihoods, and } \\
\text { expectations of different } \\
\text { stakeholder groups? }\end{array}$ & $\begin{array}{l}\text { Identify complementary management and } \\
\text { adaptation options (e.g., stewardship programs, } \\
\text { corridors, community conservation). } \\
\text { Evaluate if conservations goals are still relevant } \\
\text { or need to be reframed to address stakeholder } \\
\text { visions while addressing future climate change. } \\
\text { Participatory workshops, face-to-face dialogues, } \\
\text { or co-production to reconcile different } \\
\text { expectations about the future. } \\
\text { Evaluate changes in perception of values about } \\
\text { the protected area and identify how to allow } \\
\text { access to conservation benefits without } \\
\text { compromising ecological integrity. }\end{array}$ & {$[48,78]$} \\
\hline $\begin{array}{l}\text { How do we improve and update } \\
\text { monitoring systems and } \\
\text { knowledge governance models } \\
\text { to facilitate strategic planning in } \\
\text { a context of high uncertainty? }\end{array}$ & $\begin{array}{l}\text { Update standards and rules (including funding) } \\
\text { to improve monitoring systems and enable action; } \\
\text { evaluate adequacy of funding. } \\
\text { Co-design strategies for knowledge } \\
\text { co-production can help identify options to } \\
\text { rearticulate knowledge governance models to } \\
\text { deal with uncertain futures. } \\
\text { Evaluate management options, identify new } \\
\text { alternatives and barriers that constrain adaptive } \\
\text { management }\end{array}$ & {$[12,48,87]$} \\
\hline $\begin{array}{l}\text { Are there options for cross-scale } \\
\text { management and knowledge } \\
\text { co-production in and outside } \\
\text { protected area boundaries? }\end{array}$ & $\begin{array}{l}\text { Consider the voices and expertise from diverse } \\
\text { stakeholders in and outside the protected area } \\
\text { to enable a dialogue and participatory strategic } \\
\text { planning. This can help evaluate responses and } \\
\text { rethink current practices while finding a balance } \\
\text { between the requirement of protected area } \\
\text { management and the social-ecological context. }\end{array}$ & [48] \\
\hline $\begin{array}{l}\text { Are decision-making processes } \\
\text { and knowledge systems still } \\
\text { valid to deal with new conditions } \\
\text { and navigate ecological change? }\end{array}$ & $\begin{array}{l}\text { Evaluate strategic alliances between different } \\
\text { groups for collecting, analysing, and sharing } \\
\text { information (e.g., private sector, academia, local } \\
\text { communities). } \\
\text { Identify which rules and norms might need to } \\
\text { change to facilitate integrating diverse } \\
\text { knowledge systems to facilitate adaptation in the } \\
\text { short and long-term }\end{array}$ & [46] \\
\hline
\end{tabular}

\section{References}

1. Star, S.L.; Griesemer, J.R. Institutional Ecology, 'Translations' and Boundary Objects: Amateurs and Professionals in Berkeley's Museum of Vertebrate Zoology, 1907-1939. Soc. Stud. Sci. 1989, 19, 387-420. [CrossRef]

2. Haffer, J. Speciation in Amazonian Forest Birds. Science 1969, 165, 131-137. [CrossRef]

3. Wakild, E. A Panorama of Parks: Deep Nature, Depopulation, and the Cadence of Conserving Nature. In $A$ Living Past; Soluri, J., Leal, C., Pádua, J.A., Eds.; Berghahn Books: New York, NY, USA, 2019; pp. 246-265.

4. Cumming, G.S.; Allen, C.R.; Ban, N.C.; Biggs, D.; Biggs, H.C.; Cumming, D.H.M.; De Vos, A.; Epstein, G.; Etienne, M.; Maciejewski, K.; et al. Understanding protected area resilience: A multiscale, social-ecological approach. Ecol. Appl. 2015, 25, 299-319. [CrossRef] [PubMed] 
5. Colloff, M.; Overton, I.C.; Henderson, B.L.; Roberts, J.; Reid, J.R.W.; Oliver, R.L.; Arthur, A.D.; Doody, T.M.; Sims, N.C.; Ye, Q.; et al. The use of historical environmental monitoring data to test predictions on cross-scale ecological responses to alterations in river flows. Aquat. Ecol. 2018, 52, 133-153. [CrossRef]

6. Ryo, M.; Aguilar-Trigueros, C.A.; Pinek, L.; Muller, L.A.; Rillig, M.C. Basic Principles of Temporal Dynamics. Trends Ecol. Evol. 2019, 34, 723-733. [CrossRef]

7. Goodall, H. Riding the Tide: Indigenous Knowledge, History and Water in a Changing Australia. Environ. Hist. 2008, 14, 355-384. [CrossRef]

8. Cilliers, P. On the importance of a certain slowness. Emerg. Complex. Organ. 2006, 8, 106-113.

9. Freitag, S.; Biggs, H.; Breen, C. The spread and maturation of strategic adaptive management within and beyond South African national parks. Ecol. Soc. 2014, 19, 19. [CrossRef]

10. Clark, W.C.; Van Kerkhoff, L.; Lebel, L.; Gallopin, G. Crafting usable knowledge for sustainable development. Proc. Natl. Acad. Sci. USA 2016, 113, 4570-4578. [CrossRef]

11. Fernández, R.J. How to be a more effective environmental scientist in management and policy contexts. Environ. Sci. Policy 2016, 64, 171-176. [CrossRef]

12. Cvitanovic, C.; McDonald, J.; Hobday, A.J. From science to action: Principles for undertaking environmental research that enables knowledge exchange and evidence-based decision-making. J. Environ. Manag. 2016, 183, 864-874. [CrossRef] [PubMed]

13. Cvitanovic, C.; Hobday, A.; Van Kerkhoff, L.; Wilson, S.K.; Dobbs, K.; Marshall, N. Improving knowledge exchange among scientists and decision-makers to facilitate the adaptive governance of marine resources: A review of knowledge and research needs. Ocean Coast. Manag. 2015, 112, 25-35. [CrossRef]

14. Hopkins, A.; McKellar, R.; Worboys, G.; Good, R. Climate change and protected areas. In Protected Area Governance and Management; Worboys, G.L., Lockwood, M., Kothari, A., Feary, S., Pulsford, I., Eds.; ANU Press: Canberra, Australia, 2015; pp. 495-530.

15. Report of the Plenary of the Intergovernmental Science-Policy Platform on Biodiversity and Ecosystem Services on the Work of its Seventh Session: Summary for Policymakers of the Global Assessment Report on Biodiversity and Ecosystem Services of the Intergovernmental Science-Policy Platform on Biodiversity and Ecosystem Service; Intergovernmental Science-Policy Platform on Biodiversity and Ecosystem Services: Paris, France, 2019.

16. Dunlop, M.; Brown, P.R. Implications of Climate Change for Australia's National Reserve System: A Preliminary Assessment. Report to the Department of Climate Change, February 2008; CSIRO: Canberra, Australia, 2008.

17. Buotte, P.C.; Peterson, D.L.; McKelvey, K.S.; Hicke, J.A. Capturing subregional variability in regional-scale climate change vulnerability assessments of natural resources. J. Environ. Manag. 2016, 169, 313-318. [CrossRef] [PubMed]

18. Múnera, C.; van Kerkhoff, L. Diversifying knowledge governance for climate adaptation in protected areas in Colombia. Environ. Sci. Policy 2019, 94, 39-48. [CrossRef]

19. Watson, J.E.M. Human responses to climate change will seriously impact biodiversity conservation: It's time we start planning for them. Conserv. Lett. 2014, 7, 1-2. [CrossRef]

20. Maxwell, S.L.; Venter, O.; Jones, K.R.; Watson, J.E. Integrating human responses to climate change into conservation vulnerability assessments and adaptation planning. Ann. N. Y. Acad. Sci. 2015, 1355, 98-118. [CrossRef]

21. Smit, I.P.; Riddell, E.S.; Cullum, C.; Petersen, R. Kruger National Park research supersites: Establishing long-term research sites for cross-disciplinary, multiscaled learning. Koedoe 2013, 55, 1-7. [CrossRef]

22. Sinclair, A.R.; Walker, B. The Kruger Experience: Ecology and Management of Savanna Heterogeneity; Islander Press: Washington, DC, USA, 2003.

23. Pasquini, L.; Cowling, R.M. Opportunities and challenges for mainstreaming ecosystem-based adaptation in local government: Evidence from the Western Cape, South Africa. Environ. Dev. Sustain. 2015, 17, 1121-1140. [CrossRef]

24. Miller, C.A. Civic Epistemologies: Constituting Knowledge and Order in Political Communities. Sociol. Compass 2008, 2, 1896-1919. [CrossRef]

25. Cook, S.N.; Wagenaar, H. Navigating the Eternally Unfolding Present: Toward an Epistemology of Practice. Am. Rev. Public Adm. 2012, 42, 3-38. [CrossRef]

26. West, S.; van Kerkhoff, L.; Wagenaar, H. Beyond "linking knowledge and action": Towards a practice-based approach to transdisciplinary sustainability interventions. Policy Stud. 2019, 40, 534-555. [CrossRef] 
27. Kolinjivadi, V.; Almeida, D.V.; Martineau, J. Can the planet really be saved in Time? On the temporalities of socionature, the clock and the limits debate. Environ. Plan. E Nat. Space 2019, 1-23. [CrossRef]

28. Bell, W. Foundations of Futures Studies: Human Science for a New Era, Volume 1, History Purposes and Knowledge; Transaction Publishers: New Jersey, NJ, USA, 1997.

29. Adger, W.N.; Dessai, S.; Goulden, M.; Hulme, M.; Lorenzoni, I.; Nelson, D.R.; Naess, L.O.; Wolf, J.; Wreford, A. Are there social limits to daptation to climate change? Clim. Chang. 2009, 93, 335-354. [CrossRef]

30. Adam, B. Timescapes of Modernity: The Environment and Invisible Hazards; Taylor \& Francis Group: London, UK, 1998.

31. Beever, A.E.; Woodward, A. Design of ecoregional monitoring in conservation areas of high-latitude ecosystems under contemporary climate change. Biol. Conserv. 2011, 144, 1258-1269. [CrossRef]

32. Rogers, K.; Biggs, H. Integrating indicators, endpoints and value systems in strategic management of the rivers of the Kruger National Park. Freshw. Biol. 1999, 41, 439-451. [CrossRef]

33. Rogers, K.; Saintilan, N.; Colloff, M.; Wen, L. Application of Thresholds of Potential Concern and Limits of Acceptable Change in the condition assessment of a significant wetland. Environ. Monit. Assess. 2013, 185, 8583-8600. [CrossRef]

34. Smit, I.P.; Archibald, S. Herbivore culling influences spatio-temporal patterns of fire in a semiarid savanna. J. Appl. Ecol. 2019, 56, 711-721. [CrossRef]

35. Clark, J.S. Ecological Forecasts: An Emerging Imperative. Science 2001, 293, 657-660. [CrossRef]

36. Cork, S. Using futures thinking to support ecosystem assessments. In Routledge Handbook of Ecosystem Services; Potschin, R.H.-Y.M., Fish, R., Turner, R.K., Eds.; Routledge: London, UK, 2015; pp. 170-187.

37. Ahvenharju, S.; Minkkinen, M.; Lalot, F. The five dimensions of Futures Consciousness. Futures 2018, 104, 1-13. [CrossRef]

38. Van Kerkhoff, L.; Pilbeam, V. Understanding socio-cultural dimensions of environmental decision-making: A knowledge governance approach. Environ. Sci. Policy 2017, 73, 29-37. [CrossRef]

39. Wenger, E. Communities of Practice: Learning, Meaning, and Identity. In Learning in Doing: Social, Cognitive and Computational Perspectives; Cambridge University Press: Cambridge, UK, 1998.

40. Roncoli, C.; Crane, T.; Orlove, B. Fielding Climate Change in Cultural Anthropology. In Anthropology and Climate Change from Encounters to Action; Crate, S.A., Nuttall, M., Eds.; Routledge: London, UK, 2009.

41. Lam, D.P.M.; Hinz, E.; Lang, D.; Tengö, M.; Von Wehrden, H.; Martín-López, B. Indigenous and local knowledge in sustainability transformations research: A literature review. Ecol. Soc. 2020, 25, 25. [CrossRef]

42. Ungar, P.; Premauer, J. Attending to the Pulses of the Territory: Local Officers, National Parks, and Indigenous Territories in Colombia. In Environmental Cultural Studies: Through Time: The Luso-Hispanic World Issues on Line; Prádanos, L.I., Beilin, K., Conolly, K., McKay, M., Eds.; Hispanic Issues On Line 24: Nashville, TN, USA, 2019; pp. 80-97.

43. Cuvi, N. Indigenous Imprints and Remnants in the Tropical Andes. In A Living Past; Soluri, J., Leal, C., Pádua, J.A., Eds.; Berghahn Books: New York, NY, USA, 2019; pp. 67-90.

44. Goldman, M.J.; Turner, M.D.; Daly, M. A Critical Political Ecology of Human Dimensions of Climate Change: Epistemology, Ontology, and Ethics. Wiley Interdiscip. Rev. Clim. Chang. 2018, 9, e526. [CrossRef]

45. Worboys, G.; Lockwood, M.; Kothari, A.; Feary, S.; Pulsford, I. Protected Area Governance and Management; IUCN, Ed.; ANU Press: Canberra, Australia, 2015.

46. Gorddard, R.; Colloff, M.; Wise, R.M.; Ware, D.; Dunlop, M. Values, rules and knowledge: Adaptation as change in the decision context. Environ. Sci. Policy 2016, 57, 60-69. [CrossRef]

47. Colloff, J.M.; Gorddard, R.; Dunlop, M. The Values-Rules-Knowledge Framework in Adaptation Decision-Making: A Primer; CSIRO Land and Water: Canberra, Australia, 2018.

48. Van Kerkhoff, L.; Munera, C.; Dudley, N.; Guevara, O.; Wyborn, C.; Figueroa, C.; Dunlop, M.; Hoyos, M.A.; Castiblanco, J.; Becerra, L. Towards future-oriented conservation: Managing protected areas in an era of climate change. Ambio 2018, 48, 699-713. [CrossRef]

49. Beier, P.; Hansen, L.J.; Helbrecht, L.; Behar, D. A how-to guide for coproduction of actionable science. Conserv. Lett. 2016, 10, 288-296. [CrossRef]

50. Wyborn, C.; Datta, A.; Montana, J.; Ryan, M.; Leith, P.; Chaffin, B.; Miller, C.; Van Kerkhoff, L. Co-Producing Sustainability: Reordering the Governance of Science, Policy, and Practice. Annu. Rev. Environ. Resour. 2019, 44, 319-346. [CrossRef] 
51. Gerritsen, L.A.; Stuiver, M.; Termeer, C.J.A.M. Knowledge governance: An exploration of principles, impact, and barriers. Sci. Public Policy 2013, 40, 604-615. [CrossRef]

52. Cash, D.W.; Clark, W.C.; Alcock, F.; Dickson, N.M.; Eckley, N.; Guston, D.H.; Jäger, J.; Mitchell, R.B. Knowledge systems for sustainable development. Proc. Natl. Acad. Sci. USA 2003, 100, 8086-8091. [CrossRef]

53. Roux, D.J.; Kingsford, R.T.; Cook, C.N.; Carruthers, J.; Dickson, K.; Hockings, M. The case for embedding researchers in conservation agencies. Conserv. Biol. 2019, 33, 1266-1274. [CrossRef]

54. Freeth, R.; Caniglia, G. Learning to collaborate while collaborating: Advancing interdisciplinary sustainability research. Sustain. Sci. 2020, 15, 247-261. [CrossRef]

55. Turner, N.; Spalding, P.R. We might go back to this; drawing on the past to meet the future in northwestern North American indigenous communities. Ecol. Soc. 2013, 18, 18. [CrossRef]

56. Dryzek, J.S.; Pickering, J. The Politics of the Anthropocene; Oxford University Press: Oxford, UK, 2019.

57. Barboza, F.R.; Ito, M.; Franz, M. Biodiversity and the Functioning of Ecosystems in the Age of Global Change: Integrating Knowledge Across Scales. In YOUMARES 8-Oceans Across Boundaries: Learning from Each Other; Jungblut, S., Liebich, V., Bode, M., Eds.; Springer International Publishing: New York, NY, USA, 2018; pp. 167-178.

58. Scholes, J. Climate Change and Ecosystem Services. WIREs Clim. Chang. 2016, 7, 537-550. [CrossRef]

59. Biggs, H.; Ferreira, S.; Ronaldson, S.F.; Grant-Biggs, R. Taking stock after a decade: Does the 'thresholds of potential concern' concept need a socio-ecological revamp? Koedoe 2011, 53, 60-68. [CrossRef]

60. Hockings, M.; Leverington, F.; Cook, C. Protected area management effectiveness. In Protected Area Governance and Management; Worboys, G.L., Lockwood, M., Kothari, A., Feary, S., Pulsford, I., Eds.; ANU Press: Canberra, Australia, 2015; pp. 889-928.

61. Gregory, R.; Ohlson, D.; Arvai, J. Deconstructing adaptive management: Criteria for applications to environmental management. Ecol. Appl. 2006, 16, 2411-2425. [CrossRef]

62. Van Wilgen, B.W.; Biggs, H.C. A critical assessment of adaptive ecosystem management in a large savanna protected area in South Africa. Biol. Conserv. 2011, 144, 1179-1187. [CrossRef]

63. Rogers, K.; Bestbier, R. Development of A Protocol for the Definition of the Desired State of Riverine Systems in South Africa; Department of Environmental Affairs and Tourism: Pretoria, South Africa, 1997.

64. Biggs, H.C.; Slotow, R.; Scholes, B.; Carruthers, J.; Van Aarde, R.; Kerley, G.; Twine, W.; Grobler, D.; Bertschinger, H.; Grant, C.; et al. Towards Integrated Decision-Making for Elephant Management. In Elephant Management: A Scientific Assessment for South Africa; Scholes, R.J., Mennell, K.G., Eds.; Wits University Press: Johannesburg, South Africa, 2008; pp. 537-586.

65. Novellie, P.; Biggs, H.; Roux, D. National laws and policies can enable or confound adaptive governance: Examples from South African national parks. Environ. Sci. Policy 2016, 66, 40-46. [CrossRef]

66. Jones, L.; Champalle, C.; Chesterman, S.; Cramer, L.; Crane, T.A. Constraining and enabling factors to using long-term climate information in decision-making. Clim. Policy 2016, 17, 551-572. [CrossRef]

67. Premauer, J.; Berkes, F. A Pluralistic Approach to Protected Area Governance: Indigenous Peoples and Makuira National Park, Colombia. Ethnobiol. Conserv. 2015, 4, 1-16.

68. Enright, N.J.; Thomas, I. Pre-European fire regimes in Australian ecosystems. Geogr. Compass 2008, 2, 979-1011. [CrossRef]

69. Ens, E.; Finlayson, M.; Preuss, K.; Jackson, S.; Holcombe, S.; Finlayson, C.M. Australian approaches for managing 'country' using Indigenous and non-Indigenous knowledge. Ecol. Manag. Restor. 2012, 13, 100-107. [CrossRef]

70. Russell-Smith, J.; Cook, G.D.; Cooke, P.M.; Edwards, A.C.; Lendrum, M.; Meyer, C.; Whitehead, P.J. Managing fire regimes in north Australian savannas: Applying Aboriginal approaches to contemporary global problems. Front. Ecol. Environ. 2013, 11 (Suppl. 1), e55-e63. [CrossRef]

71. Tanner-McAllister, S.L.; Rhodes, J.; Hockings, M. Managing for climate change on protected areas: An adaptive management decision making framework. J. Environ. Manag. 2017, 204, 510-518. [CrossRef] [PubMed]

72. Steffensen, V. Fire Country: How Indigenous Fire Management Could Help Save Australia; Hardie Grant Travel: Melbourne, Australia, 2020; p. 240.

73. Hirsch, S.L.; Long, J. Adaptive Epistemologies: Conceptualizing Adaptation to Climate Change in Environmental Science. Sci. Technol. Hum. Values 2020. [CrossRef] 
74. Cornell, S.E.; Berkhout, F.; Tuinstra, W.; Tàbara, J.D.; Jäger, J.; Chabay, I.; De Wit, B.; Langlais, R.; Mills, D.; Moll, P.; et al. Opening up knowledge systems for better response to global environmental change. Environ. Sci. Policy 2013, 28, 60-70. [CrossRef]

75. Dovers, S.R.; Hezri, A.A. Institutions and policy processes: The means to the ends of adaptation. Wiley Interdiscip. Rev. Clim. Chang. 2010, 1, 212-231. [CrossRef]

76. Lemieux, C.J.; Beechey, T.J.; Gray, P.A. Prospects for Canada's protected areas in an era of rapid climate change. Land Use Policy 2011, 28, 928-941. [CrossRef]

77. Pearson, S.; Lynch, A.J.J.; Plant, R.; Cork, S.; Taffs, K.H.; Dodson, J.; Maynard, S.; Gergis, J.; Gell, P.; Thackway, R.; et al. Increasing the understanding and use of natural archives of ecosystem services, resilience and thresholds to improve policy, science and practice. Holocene 2015, 25, 366-378. [CrossRef]

78. Johnson, F.A.; Eaton, M.J.; McMahon, G.; Nilius, R.; Bryant, M.R.; Case, D.J.; Martin, J.; Wood, N.J.; Taylor, L. Global change and conservation triage on National Wildlife Refuges. Ecol. Soc. 2015, 20, 14. [CrossRef]

79. Isbell, F.; Gonzalez, A.; Loreau, M.; Cowles, J.; Díaz, S.; Hector, A.; Mace, G.M.; Wardle, D.A.; O'Connor, M.I.; Duffy, J.E.; et al. Linking the influence and dependence of people on biodiversity across scales. Nature 2017, 546, 65-72. [CrossRef]

80. Biggs, H.C.; Rogers, K.H. An adaptive system to link science, monitoring and management in practice. In The Kruger Experience: Ecology and Management of Savanna Heterogeneity; Sinclair, A.R., Walker, B., Eds.; Island Press: Washington, DC, USA, 2003; pp. 59-80.

81. Moon, K.; Blackman, D. A Guide to Understanding Social Science Research for Natural Scientists. Conserv. Biol. 2014, 28, 1167-1177. [CrossRef]

82. Groves, C.R.; Game, E.T.; Anderson, M.G.; Cross, M.; Enquist, C.; Ferdaña, Z.; Girvetz, E.; Gondor, A.; Hall, K.R.; Higgins, J.; et al. Incorporating climate change into systematic conservation planning. Biodivers. Conserv. 2012, 21, 1651-1671. [CrossRef]

83. Moon, K.; Guerrero, A.M.; Adams, V.M.; Biggs, D.; Blackman, D.A.; Craven, L.; Dickinson, H.; Ross, H. Mental models for conservation research and practice. Conserv. Lett. 2019, 12, e12642. [CrossRef]

84. Jordan, C.; Urquhart, G.; Kramer, D. On Using Mental Model Interviews to Improve Camera Trapping: Adapting Research to Costeño Environmental Knowledge. Conserv. Soc. 2013, 11, 159-175. [CrossRef]

85. Wyborn, C.; Van Kerkhoff, L.; Dunlop, M.; Dudley, N.; Guevara, O. Future oriented conservation: Knowledge governance, uncertainty and learning. Biodivers. Conserv. 2016, 25, 1401-1408. [CrossRef]

86. Hermans, L.; Haasnoot, M.; Ter Maat, J.; Kwakkel, J.H. Designing monitoring arrangements for collaborative learning about adaptation pathways. Environ. Sci. Policy 2017, 69, 29-38. [CrossRef]

87. Dixon, K.M.; Cary, G.J.; Worboys, G.L.; Banks, S.C.; Gibbons, P. Features associated with effective biodiversity monitoring and evaluation. Biol. Conserv. 2019, 238, 108221. [CrossRef] 